\title{
O JOGO COMO FERRAMENTA DE APOIO AO PROGRAMA ARQUITETÔNICO DE ESCOLAS PÚBLICAS
}

\section{A GAME AS A TOOL TO SUPPORT THE ARCHITECTURAL PROGRAM OF PUBLIC SCHOOL BUILDING}

\author{
Marcella Savioli Deliberador ${ }^{1}$ \\ Universidade Estadual de Campinas- UNICAMP, Campinas, SP, Brasil, marcelladeliberador@yahoo.com.br \\ Doris C.C.K. Kowaltowski 2 \\ Universidade Estadual de Campinas- UNICAMP, Campinas, SP, Brasil, doris@fec.unicamp.br
}

\section{Resumo}

Este artigo apresenta os resultados de uma pesquisa sobre o desenvolvimento de uma ferramenta de apoio ao processo de projeto de escolas públicas. O objetivo é aprofundar a discussão sobre a arquitetura escolar, destacando-se o programa arquitetônico e os processos participativos. A relevância dessa pesquisa relaciona-se com a importância da qualidade do ambiente físico escolar, aspecto que ganhou destaque internacional com a divulgação de pesquisas que demonstram a relação entre a qualidade desses espaços e a capacidade de aprendizagem dos alunos. Processos participativos demandam protocolos e ferramentas de apoio, com conteúdo baseado em pesquisas científicas que apresentam os parâmetros de projeto, considerados indispensáveis à arquitetura de qualidade. A ferramenta, em formato de um jogo de cartas, está baseada em parâmetros de projeto específicos da realidade brasileira, a partir dos requisitos da Fundação para o Desenvolvimento da Educação e da literatura. O jogo foi elaborado à semelhança de um baralho, apresentando as temáticas consideradas importantes à arquitetura escolar. Cada carta representa um parâmetro de projeto. O jogo foi testado com grupos de profissionais e com alunos de arquitetura. Em ambas as situações, a ferramenta mostrou-se um eficiente instrumento de estímulo às discussões, apoio ao processo participativo de projeto e ao desenvolvimento do programa arquitetônico. O jogo apresenta-se como uma contribuição na área de metodologia de projeto, oferecendo suporte ao programa arquitetônico, através de um debate estruturado. O programa deve se constituir em um documento que alimenta as fases seguintes de projeto arquitetônico e estimular propostas inovadoras, oferecendo uma contribuição para a melhoria da educação.

Palavras-chave: Arquitetura escolar. Processo de projeto. Projeto participativo. Programa arquitetônico. Jogos.

\begin{abstract}
This article presents the results of the development of an architectural programming tool for the design of public school in the state of São Paulo, Brazil. The main goal of the tool is to support and encourage discussion on the themes of school design, mainly to support architectural programming and the participatory design process. The importance of this research is related to the school spaces, because many international publications showed the relation between the quality of these spaces and the learning capacity of the students. The game is based on design patterns, found in the literature on school building design and is adapted to the Brazilian reality. Technical and specific design requirements from FDE (Fundação para o Desenvolvimento da Educação) were used to adapt global parameters to local conditions. The tool is in the form of a card game, with 17 suits of 4 cards each. Each suit represents an important design theme. Each card is organized like a pattern with graphic and verbal information on a specific concept. The card game was tested in two different contexts: first with groups of professionals, scholars, architects, teachers, students, parents, engineers and principals of schools. Secondly test occurred with architecture students. Both situations showed that the game is an efficient tool to stimulate school design discussions and to help designers to elaborate the Architectural Program. The card game presents itself as a contribution to the area of design methods to support the architectural programming phase. The format of the tool also stimulates a structured debate, focusing the participant's attention on the topic at hand and producing a final effective product to enhance the next phase of a school design process.
\end{abstract}

Keywords: School architecture. Design process. Participatory design. Architectural program. Games.

How to cite this article:

DELIBERADOR, Marcella Savioli; KOWALTOWSKI, Doris Catharine Cornelie Knatz. O jogo como ferramenta de apoio ao programa arquitetônico de escolas públicas. PARC Pesquisa em Arquitetura e Construção, Campinas, SP, v. 6, n. 2, p. 85-102, jun. 2015. ISSN $1980-6809$.

Disponível em: <http://periodicos.sbu.unicamp.br/ojs/index.php/parc/article/view/8634985>. Acesso em: 19 out. 2015. 


\section{Introdução}

Muitos são os profissionais envolvidos na reflexão sobre a necessária mudança na educação do Brasil, principalmente em razão dos baixos índices de desempenho obtidos nas avaliações aplicadas junto aos alunos das escolas públicas (DELIBERADOR, 2010).

O Censo Escolar (INEP, 2015) constitui-se no principal instrumento de coleta de informações sobre a educação básica e aponta a existência de vários problemas na educação brasileira, especialmente quando se trata das escolas públicas. Embora a maior parte das crianças brasileiras do Ensino Fundamental encontrarem-se matriculadas, a qualidade do ensino a elas oferecido ainda apresenta problemas (MEC, 2015b).

A melhoria da educação é, portanto, um importante desafio atual, especialmente ao buscar-se diminuir as desigualdades existentes no Brasil. Uma tarefa de tal alcance, para ser bem-sucedida, impõe a necessidade de abordagens multidisciplinares que vislumbrem a melhoria da educação como um todo. Entre tais abordagens, destaca-se a arquitetura escolar, área do conhecimento que pode contribuir para a superação de fragilidades existentes no sistema educacional brasileiro.

Avaliações Pós-Ocupação (APO), análise de bons projetos precedentes, discussão e crítica sobre esses projetos podem embasar o trabalho dos projetistas. A função primordial desses profissionais é a proposição de soluções arquitetônicas mais adequadas às necessidades pedagógicas impostas pelas novas demandas sociais. Desse modo, a abordagem espacial, cada vez mais apontada como capaz de influenciar a qualidade do aprendizado dos alunos, torna-se elemento essencial no pensamento de uma educação qualificada (SANOFF, 2001; EARTHMAN; 2002; TARALLI, 2004; FISHER, 2007; DURÁN-NARUCKI; 2008; CABE, 2009).

No Brasil, as APO's de escolas indicam falhas, que podem ter sido originadas em função de possíveis lacunas existentes no processo de projeto e de obra (ORNSTEIN et al., 2009; ORNSTEIN, 2012; KOWALTOWSKI; DELIBERADOR; PEREIRA, 2013; ANTUNES et al., 2014; FRANÇA; ORNSTEIN, 2014; ELALI; SOUZA, 2011). Essa observação justificou a caracterização do processo de projeto dos arquitetos da Fundação para o Desenvolvimento da Educação (FDE), para levantar oportunidades de intervenção visando a melhorias do ambiente escolar (DELIBERADOR, 2010). A conclusão dessa caracterização indicou alguns problemas no processo de projeto, destacando-se a rigidez do programa arquitetônico e o pouco espaço para inovações, resultando em edifícios similares, e, por vezes, na reincidência de problemas.

Em função dos argumentos expostos acima, este artigo apresenta os resultados de uma pesquisa sobre o desenvolvimento de uma ferramenta de apoio à etapa de programa arquitetônico escolar, no formato de um jogo de cartas. Entende-se que esse tipo de apoio é uma iniciativa na direção de buscar meios capazes de ampliar a qualidade do projeto e do espaço. Dessa forma, contribui-se com a melhoria do processo de projeto e, indiretamente, de seu produto, o edifício escolar.

\section{Processo de projeto da FDE}

Em termos da concepção das escolas públicas, sabe-se que, dependendo do grau de escolarização, essa é de responsabilidade do Estado ou do município. Esta pesquisa foca-se nas escolas estaduais de São Paulo, gerenciadas pela Fundação para o Desenvolvimento da Educação (FDE), ou seja, escolas direcionadas ao Ensino Fundamental e Médio. Esse recorte justifica-se, uma vez que essa instituição gerencia e mantém mais de 5000 escolas no Estado de São Paulo, acumulando ampla experiência, inclusive por ser responsável pela manutenção dos edifícios escolares. Tais fatos a tornam referência para outros estados do país, aumentando sua importância e a influência das práticas por ela adotadas.

O processo de projeto da FDE é realizado, atualmente, a partir de concursos públicos, que avaliam quesitos relacionados à técnica e ao preço dos proponentes, apresentados em estudos de anteprojeto. Todas as diretrizes de projeto são indicadas por meio de catálogos técnicos dos componentes pré-moldados, o que facilita a licitação da obra e sua execução. O projeto que obtém maior nota no conjunto é selecionado e contratado para ser desenvolvido até a fase de Projeto Executivo. A partir daí, procede-se a licitação de obra (FDE, 2015).

Buscando conhecimento aprofundado sobre o processo de projeto da FDE, esse foi caracterizado (DELIBERADOR, 2010). Observou-se seu caráter excessivamente linear, conforme demonstrado no esquema da Figura 1, com poucas possibilidades de realimentação aos novos processos. A ausência da participação da comunidade na definição do programa arquitetônico foi outra característica destacada na literatura específica e ausente no processo atual. Sabese da dificuldade em organizar a participação efetiva de todos os envolvidos, característica essencial para a garantia de processos realmente colaborativos e produtivos (WOOLNER, 2009; DELIBERADOR, 2010). 


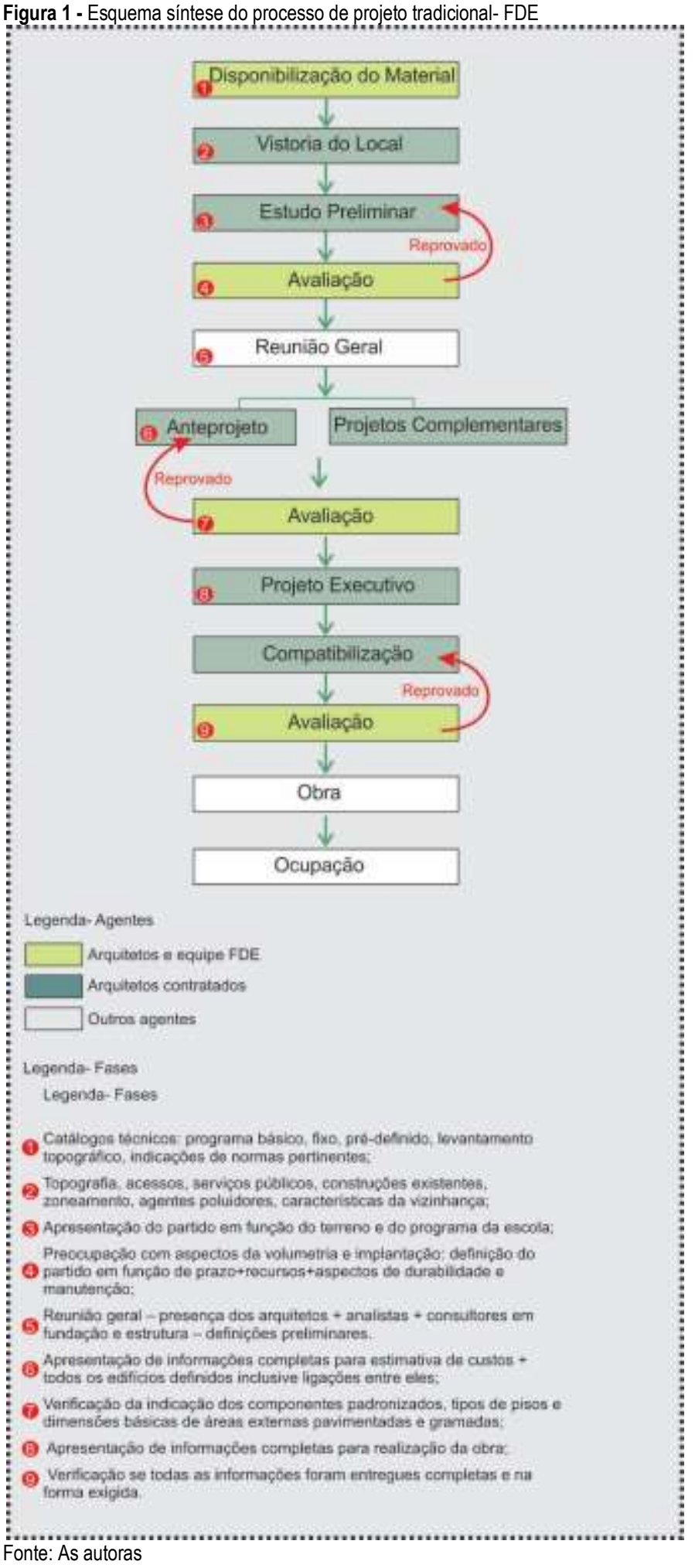

A caracterização também destacou aspectos positivos e delineou algumas possibilidades de melhoria, destacando a necessidade da criação de ferramentas de apoio ao processo de projeto. Muitas são as etapas em que essa intervenção se mostra importante, destacandose a fase do programa arquitetônico (KOWALTOWSKI; MOREIRA; DELIBERADOR, 2012).
Grande parte dos programas arquitetônicos das escolas públicas brasileiras é realizada com base em necessidades pré-determinadas pelas Secretarias ou Ministérios da Educação, sem incluir a participação dos profissionais da área. Dever-se-ia iniciar o processo de planejamento de ambientes de ensino com ampla discussão sobre as melhores práticas em educação (TAYLOR; ENGGASS, 2008). Desse modo surgiriam oportunidades de reflexão sobre as escolas, suas metodologias, potencialidades, fragilidades e dificuldades, advindas de variados âmbitos. Se essas questões não são refletidas durante o processo de programação, podem ser necessários ajustes e adaptações no edifício, ocasionando perda de funcionalidade, de conforto ambiental entre outros problemas, comumente identificados nas APOs realizadas em escolas brasileiras (PEREIRA, 2013)

\section{Pedagogia e ambiente escolar}

A literatura sobre arquitetura escolar é ampla e geralmente discute as tendências pedagógicas e as respostas arquitetônicas a elas oferecidas (SANOFF, 1994; DUDEK, 2007; NAIR; FIELDING; LACKNEY, 2009; DESIGN; FURNITURE; DESIGN, 2010; WOOLNER, 2010; HILLE, 2011). Muitos são os aspectos considerados para a obtenção de uma arquitetura escolar de qualidade e eles precisam estar em acordo com as realidades em que serão inseridos. Os espaços devem ser projetados para que estimulem a curiosidade natural dos alunos, transformando a arquitetura em uma ferramenta de aprendizado (TAYLOR; ENGGASS, 2008).

As escolas devem responder adequadamente às questões de estética, conforto, segurança e saúde, mas também não podem desligar-se das questões pedagógicas e culturais específicas. Isso indica a necessidade de serem incorporados os aspectos pedagógicos já na fase do programa arquitetônico que determinam as atividades de ensino e seu reflexo para a sua ambientação. A comunicação efetiva entre educadores e arquitetos é um pré-requisito essencial para o planejamento e projeto de sucesso, especialmente quando se busca ampliar os limites dos modelos convencionais de educação (WALDEN, 2009).

A bibliografia sobre metodologias pedagógicas sinaliza novos paradigmas que pressupõem flexibilidade de uso dos espaços com presença de maior variedade de configurações (BUILDING FUTURES, 2004; HIGGINS et al., 2005; FISHER, 2007; TAYLOR; ENGGASS, 2008). A escola pública brasileira está em busca de assumir uma nova identidade, a partir de responsabilidades e compromissos sociais bem mais 
amplos do que a escola tradicional estava acostumada a propiciar (CAVALIERE, 2002). Esses edifícios não podem se resumir a salas de aula: precisam incluir espaços de estudo individuais e em grupo, laboratórios específicos, espaços de convívio diversos, entre outros que possibilitem a experiência de aprendizado na sua plenitude (TAYLOR; ENGGASS, 2008).

\section{0 programa e os parâmetros projetuais}

A literatura indica um processo de referência para alcançar projetos de alto padrão de desempenho. Esse processo coloca o programa arquitetônico em posição de destaque. O desafio é conduzir um processo de programação que alimente o processo criativo de projeto, incluindo a participação dos futuros usuários. A fase de programação é, em sua essência, uma etapa analítica e que exige ferramentas de apoio para que as reflexões sejam aprofundadas (MOREIRA; KOWALTOWSKI, 2009). Esse programa deve se constituir em um documento que apresenta metas, fatos, conceitos, indicadores de avaliação e desempenho e dados que alimentam as próximas fases do processo de projeto.

Cada solicitação para um novo projeto deveria ser entendida como um novo problema a ser resolvido, com características e demandas próprias a serem consideradas (TAYLOR; ENGGASS, 2008). O programa arquitetônico articula valores, aos quais o arquiteto deverá responder em suas propostas. Crenças, filosofias, ideologias, propósitos e ideias que expressam a razão do edifício necessitam de reflexão e introdução no programa (HERSHBERGER, 1999). Dessa forma, a realização de um processo de projeto escolar deveria incluir os agentes responsáveis por um novo edifício (alunos, pais, professores, funcionários, arquitetos, construtores e membros da comunidade) para externarem os seus valores (DUDEK, 2000; CABE, 2004).

Para a fase do programa, algumas metodologias já foram exploradas e variadas são as possibilidades de organização dos dados. Destacam-se os métodos de Sanoff (2001); o Problem Seeking (PEÑA; PARSHALL; 2012) e a ISO 9699:1994. A utilização de métodos é importante para a condução do processo de programação e a organização do conteúdo, com parâmetros de projeto originados dos processos participativos e da literatura específica.

A literatura destaca a importância do levantamento de parâmetros de projeto adequados à realidade em que o projeto deverá ser implantado. A definição desses parâmetros surge a partir dos trabalhos da década de 70, de Christopher Alexander que propôs a utilização desse conceito como uma metodologia de projeto (ALEXANDER; ISHIKAWA.; SILVERSTEIN, 2013). O autor denominou tais configurações de patterns, cuja tradução mais aproximada é parâmetros de projeto.

Alguns parâmetros específicos da realidade escolar já foram desenvolvidos. Os autores, Nair, Fielding e Lackney (2009), por exemplo, utilizaram-se dessa linguagem para a proposição de 28 parâmetros específicos para a realidade escolar, traduzidos por Kowaltowski (2011). Existem outros parâmetros importantes dispersos pela literatura, tornando-se importante sua organização para que possam ser, de fato, aplicados no processo de projeto. Deve-se considerar também a adequação desses parâmetros à realidade brasileira. Nesse sentido, este trabalho buscou relacionar os parâmetros encontrados na literatura e os requisitos de projeto da FDE (PEREIRA, 2013), estruturando um grupo de temáticas representativas das questões inerentes ao processo de projeto das escolas públicas brasileiras, que irão servir de base para o desenvolvimento da ferramenta de apoio ao programa arquitetônico (Quadro 1)

\section{Os jogos como ferramentas de apoio}

Os processos de projeto atuais tornaram-se uma atividade social entre pessoas que negociam, fazem propostas e definem regras para o desenvolvimento do projeto. De forma resumida, o ato de projetar envolve acordos e a criação de regras (HABRAKEN; GROSS, 1988). As metodologias de projeto na sua maioria são ou de análise/ avaliação de projetos ou de simulação. Os métodos de apoio ao processo participativo dividem-se, na sua maioria, em atividades de walkthrough, poemas de desejo ou comparação de alternativas. Faltam ferramentas que apoiem o processo participativo de projeto que, além de apresentarem conteúdos necessários, também estimulem a discussão e resultem em um produto capaz de apoiar as etapas seguintes do processo. A organização da colaboração entre diferentes pessoas, com diferentes competências e interesses, é um desafio aos arquitetos, que necessitam de ferramentas que ofereçam suporte a esse tipo de processo (BRANDT, 2006).

Os jogos são técnicas para serem usadas quando as condições de composição de uma equipe e o tipo de projeto em questão demandam um consenso no processo de tomada de decisão (PEÑA; PARSHALL, 2001). 
DELIBERADOR, M.S.; KOWALTOWSKI, D.C.C.K

O jogo como ferramenta de apoio ao programa arquitetônico de escolas públicas

Quadro 1 - Parâmetros do processo de projeto escolar brasileiro

\begin{tabular}{|c|c|c|}
\hline Temática & Requisitos FDE (baseados em Pereira, 2013) & Parâmetros mencionados na literatura \\
\hline $\begin{array}{l}\text { Pedagogia e Modalidades } \\
\text { de Ensino }\end{array}$ & $\begin{array}{l}\text { Escola dentro da escola; relação espaço e metodologias } \\
\text { pedagógicas; espaços variados de aprendizagem, instalações para } \\
\text { necessidades pedagógicas específicas. }\end{array}$ & $\begin{array}{l}\text { Campfire; Watering Hole Space; Cave Space; Projetos } \\
\text { para inteligências múltiplas; recursos de aprendizagem } \\
\text { compartilhados; salas multi uso }\end{array}$ \\
\hline Inserção Urbana & $\begin{array}{l}\text { Acessos organizados, setorizados e acessíveis, entrada principal } \\
\text { separada das demais, reforçar a essência da escola, maximizar as } \\
\text { vantagens naturais do local, boa localização no contexto urbano, } \\
\text { definir materiais relacionados à cultura local }\end{array}$ & $\begin{array}{l}\text { Entrada convidativa e supervisionada, Conexão espaço } \\
\text { interno e externo; assinatura local; conexão com a } \\
\text { comunidade }\end{array}$ \\
\hline Espaços de Ensino & $\begin{array}{l}\text { Layout flexível, infra estrutura elétrica de acordo com os propósitos } \\
\text { da pedagogia, possibilidade de aprender com o edifício, permitir o } \\
\text { controle do ambiente pelos usuários }\end{array}$ & $\begin{array}{l}\text { Salas de Aula, espaços de ensino e comunidades } \\
\text { pequenas de aprendizado; Conexão espaço interno e } \\
\text { externo }\end{array}$ \\
\hline Pátios & Aprender com o edifício & $\begin{array}{l}\text { Áreas para brincadeira, movimento, contato com a } \\
\text { natureza, áreas de descanso e regeneração, espaços de } \\
\text { ensino na área externa }\end{array}$ \\
\hline $\begin{array}{l}\text { Ambientes } \\
\text { Especiais }\end{array}$ & Laboratório, biblioteca & $\begin{array}{l}\text { Laboratórios de Ciências, artes e área para } \\
\text { desenvolvimento de habilidades para a vida cotidiana; } \\
\text { música, atuação, esportes, educação física e saúde; } \\
\text { Conexão espaço interno e externo }\end{array}$ \\
\hline $\begin{array}{l}\text { Áreas } \\
\text { Sociais }\end{array}$ & $\begin{array}{l}\text { Relacionar espaços de alimentação, socialização e artes; espaços de } \\
\text { alimentação descentralizados e ambientes internos que permitam } \\
\text { interação social }\end{array}$ & $\begin{array}{l}\text { Espaços de Exposição dos trabalhos dos alunos; áreas } \\
\text { de alimentação; mobiliário macio, flexível e de fácil } \\
\text { movimentação; nichos para aprendizado; espaços de } \\
\text { reunião }\end{array}$ \\
\hline $\begin{array}{l}\text { Ambientes } \\
\text { De Apoio }\end{array}$ & Administração, Cozinha & $\begin{array}{l}\text { Sala de professores equipada e com áreas de } \\
\text { alimentação e descanso; Cozinhas e Depósitos } \\
\text { adequados; Espaços administrativos }\end{array}$ \\
\hline $\begin{array}{l}\text { Espaços de } \\
\text { Serviço }\end{array}$ & $\begin{array}{l}\text { Acesso fácil aos serviços da escola; sanitários privativos; armários } \\
\text { individuais aos alunos }\end{array}$ & $\begin{array}{l}\text { Espaço individual de armazenamento de materiais; } \\
\text { "banheiros como os de casa" }\end{array}$ \\
\hline Circulação & Incorporar espaços de aprendizado nos espaços de circulação & $\begin{array}{l}\text { Generosos, seguros e com elementos capazes de } \\
\text { humanizar essas áreas (nichos e mobiliários por ex) }\end{array}$ \\
\hline $\begin{array}{l}\text { Conforto } \\
\text { Ambiental }\end{array}$ & $\begin{array}{l}\text { Funcionalidade: espaços com tamanho exato para suas funções; } \\
\text { evitar congestionamento nos corredores; boa conexão visual com o } \\
\text { exterior } \\
\text { Luminoso: iluminação natural; interferência da iluminação sobre } \\
\text { equipamentos internos; } \\
\text { Acústico: qualidade acústica; zoneamento acústico; soluções } \\
\text { acústicas para ruídos internos; } \\
\text { Térmico: Proteção contra chuva e sol nos espaços externos; } \\
\text { ventilação natural; qualidade térmica; medidas passivas para que o } \\
\text { ar seja fresco durante o dia; }\end{array}$ & $\begin{array}{l}\text { Espaços flexíveis, adaptados e variados; lluminação } \\
\text { natural e energia solar; Ventilação natural; lluminação, } \\
\text { cor e aprendizagem }\end{array}$ \\
\hline Conceitos & $\begin{array}{l}\text { Sustentabilidade: implantar esses conceitos incluindo aspectos de } \\
\text { conservação de energia, consumo de água, materiais, entre outros. } \\
\text { Acessibilidade: Prever acessos livres de barreiras e à todos; vagas } \\
\text { de estacionamento suficientes e acessiveis } \\
\text { Tecnologia Distribuída: Prever espaço para trabalhar com a } \\
\text { tecnologia e com pesquisa (wireless) }\end{array}$ & $\begin{array}{l}\text { Tecnologia Distribuída; Sustentabilidade; Humanização } \\
\text { (escala humana); Acessibilidade (wayfinding); segurança }\end{array}$ \\
\hline $\begin{array}{l}\text { Psicologia } \\
\text { Ambiental }\end{array}$ & $\begin{array}{l}\text { Prever espaços para atividades individuais ou em grupos; usar cores } \\
\text { para identificar partes do edifício; Densidade }\end{array}$ & ינ-ב- \\
\hline $\begin{array}{l}\text { Aspectos de } \\
\text { Comportamento }\end{array}$ & & $\begin{array}{l}\text { Relação entre espaço construído e comportamento nas } \\
\text { escolas. }\end{array}$ \\
\hline Público Alvo & ----- & $\begin{array}{l}\text { Criação de espaços que ofereça as melhores condições } \\
\text { de trabalho possiveis a toda a equipe }\end{array}$ \\
\hline Áreas & Aproveitar área disponível; Permitir espaços para ampliações futuras & ----- \\
\hline Zoneamento & $\begin{array}{l}\text { Prever setorização que facilite isolar áreas privadas; Permitir espaços } \\
\text { para ampliações futuras }\end{array}$ & ------ \\
\hline
\end{tabular}

Fonte: As autoras

O desenvolvimento de jogos conceituais de projeto parece ser uma abordagem promissora para oferecer suporte aos diferentes agentes nos processos colaborativos participativos (BRANDT; MESSETER, 2004).
Diversas são as razões apresentadas pela literatura para justificar os jogos nos processos de projeto. Primeiro, pode-se mencionar a ampla variedade de jogos existentes. Em segundo lugar, os jogos podem propor sistemas capazes de organizar a participação dos envolvidos, com a principal vantagem de permitir a 
criação de um cenário comum, em que todos podem se relacionar (BRANDT, 2006). Com um formato conhecido de jogo, como por exemplo o jogo de cartas, a familiaridade dos participantes com o tipo de ferramenta facilita sua aplicação, além de propiciar uma maior apropriação do jogo por parte dos usuários. Isso possibilita o aprofundamento dos aspectos mais relevantes dos projetos, considerando os diversos tipos de usuários envolvidos. A partir das discussões geradas, podem-se elaborar as questões primordiais e seu grau de importância para a busca de soluções mais adequadas.

Outros benefícios da utilização dessa técnica é que ela demanda conhecimento e estudo da ferramenta, mas não alguma habilidade específica para sua utilização. Aumenta-se a compreensão das questões do projeto e de sua complexidade e, consequentemente, o compromisso dos envolvidos. Também se obtém mais facilmente o consenso quanto a arranjos básicos do que com métodos tradicionais de busca de soluções (PEÑA; PARSHALL, 2001). Além disso, os jogos exploratórios de projeto podem engajar e divertir as pessoas, estimulando-as a participarem desse tipo de atividade e criando uma atmosfera informal bastante produtiva no campo da criatividade. As definições dos jogos dependem do escopo a ser atingido, quem são os participantes envolvidos e também dos recursos disponíveis.

No caso da tipologia escolar brasileira, o apoio no formato de jogos ainda não é comum em processos de projeto. A ferramenta de apoio desenvolvida nesta pesquisa pretende estimular os debates, de forma a garantir maior qualidade das informações obtidas na elaboração do programa arquitetônico, assim como colaborar para a condução ética nos processos de projeto participativos.

\section{Procedimentos Metodológicos}

A pesquisa configura-se, em termos metodológicos, como um estudo de levantamento e desenvolvimento de ferramenta de apoio ao programa arquitetônico, com validação a partir de testes exploratórios (GIL, 2008). Para esses testes foram estabelecidos dois objetivos principais: a avaliação da compreensão do conteúdo (parâmetros de projeto para a arquitetura escolar) e a avaliação da efetividade da ferramenta no estímulo aos debates sobre a arquitetura escolar na etapa de programação. Escolheram-se, como recorte, os edifícios públicos escolares do Estado de São Paulo, projetados e gerenciados pela FDE, ou seja, escolas de nível Fundamental I e II e de Ensino Médio. Para o desenvolvimento da pesquisa, foram estabelecidas as etapas a seguir.

\section{Etapa I- Desenvolvimento da ferramenta}

Esta etapa foi desenvolvida em três partes: (a) Definição do tipo de ferramenta; (b) Seleção do conjunto de parâmetros de projeto e naipes do jogo e (c) Transformação do conjunto de parâmetros para o formato do jogo de cartas.

$\mathrm{Na}$ definição do tipo de ferramenta de apoio foram escolhidos os jogos como orientadores do desenvolvimento da ferramenta, em razão de sua aplicabilidade para a tipologia em questão e das vantagens apresentadas anteriormente. $\mathrm{O}$ jogo foi concebido à semelhança de um baralho, ou seja, está dividido em naipes. Cada naipe representa uma temática específica da arquitetura escolar e possui 04 cartas, cada uma com um parâmetro relativo à temática. A definição do número 04 deve-se aos limites cognitivos relativos à memorização do ser humano (WEINSCHENK, 2011).

Na seleção do conjunto de parâmetros de projeto e dos naipes do jogo o conteúdo da ferramenta de apoio foi preparado, focando-se nos parâmetros de projeto da tipologia escolar. O levantamento de parâmetros foi realizado a partir da revisão da literatura e foi adequado à realidade dos projetos brasileiros, conforme apresentado no Quadro 01.

A transformação do conjunto de parâmetros para o formato do jogo de cartas realizou-se de acordo com a proposta de Alexander, Ishikawa, e Silverstein. (2013) onde: um parâmetro de projeto deve expressar um conceito a partir de um argumento (texto e diagramas), deve ser representado por uma ilustração (desenhos, diagramas ou fotos) e apresentar um título descritivo e claro. Assim, nesta etapa, definiram-se o formato da carta, as imagens representativas de cada parâmetro, assim como as palavras de apoio que devem fomentar o início da discussão. A definição das imagens foi feita a partir da divisão dos naipes em grupos: alguns deveriam ter símbolos (naipes conceituais), outros deveriam ilustrar ambientes (naipes que representavam espaços propriamente ditos) e outros deveriam apresentar fórmulas, números, etc. (naipes com dados objetivos). Desse modo, o jogo foi definido a partir de 17 naipes.

\section{Etapa II- Testes exploratórios}

Nesta etapa realizaram-se testes: de verificação da compreensão, de verificação da capacidade de apoio da ferramenta ao desenvolvimento do programa arquitetônico e de verificação da capacidade da ferramenta de apoio ao processo participativo. 


\section{Teste de verificação da compreensão do conteúdo pelos possíveis participantes do jogo de cartas}

Para essa verificação foram selecionados dois tipos de testes:

- Teste I - Um arquiteto com experiência em ilustrações e em arquitetura escolar foi convidado para analisar o jogo de cartas. Todas as cartas foram individualmente avaliadas pelo profissional, que indicava se o parâmetro estava bem representado e se as palavras de apoio estavam claras e de acordo com o parâmetro. Este teste teve por objetivo uma avaliação geral da ferramenta.

- Teste II - Foram organizados grupos de profissionais envolvidos com a tipologia escolar, ou seja, arquitetos, engenheiros, pedagogos, professores, funcionários da administração pública, etc. para testar a ferramenta. O jogo foi apresentado naipe por naipe e solicitado que os participantes simulassem um projeto escolar, no qual as definições sobre pedagogia, tamanho, terreno, etc. eram livres. Solicitou-se a ordenação das prioridades para cada naipe. Para documentar as decisões, foi utilizado o formulário da Figura 2. Ao final, os participantes foram questionados sobre a percepção geral da ferramenta e sobre outros parâmetros que considerariam importantes e que não estavam presentes no jogo.

Teste de verificação da capacidade da ferramenta apoiar o desenvolvimento da programação arquitetônica escolar

Para este teste foram realizadas três rodadas, entre estudantes de terceiro ano de duas faculdades de arquitetura e urbanismo, inscritos em disciplinas de projeto focadas no desenvolvimento da tipologia escolar. $\mathrm{O}$ objetivo foi testar a ferramenta quanto à sua possibilidade de conduzir a elaboração de programas arquitetônicos escolares completos, no âmbito educacional. Em um primeiro momento, todo o grupo de alunos participou de uma breve aula sobre programa arquitetônico. $\mathrm{Na}$ sequência, o grupo foi dividido em duas turmas de aproximadamente 12 alunos e aplicouse o jogo através da ordenação das prioridades, como no teste anterior (II). Apresentou-se a ferramenta como um todo. $\mathrm{Na}$ sequência, duplas de alunos receberam um naipe cada, para realizar o programa detalhado da temática do naipe recebido. Dessa forma, ao final da seção, cada dupla disponibilizou sua temática para as demais, de modo a se constituir uma base coletiva para o desenvolvimento do programa. Com o material de todos os naipes em mãos, cada dupla de projeto definiu suas próprias orientações e finalizou a elaboração do seu próprio programa.
Figura 2 - Exemplo de formulário motivador da discussão inicial Jogo de Cartas: Arquitetura Escolar

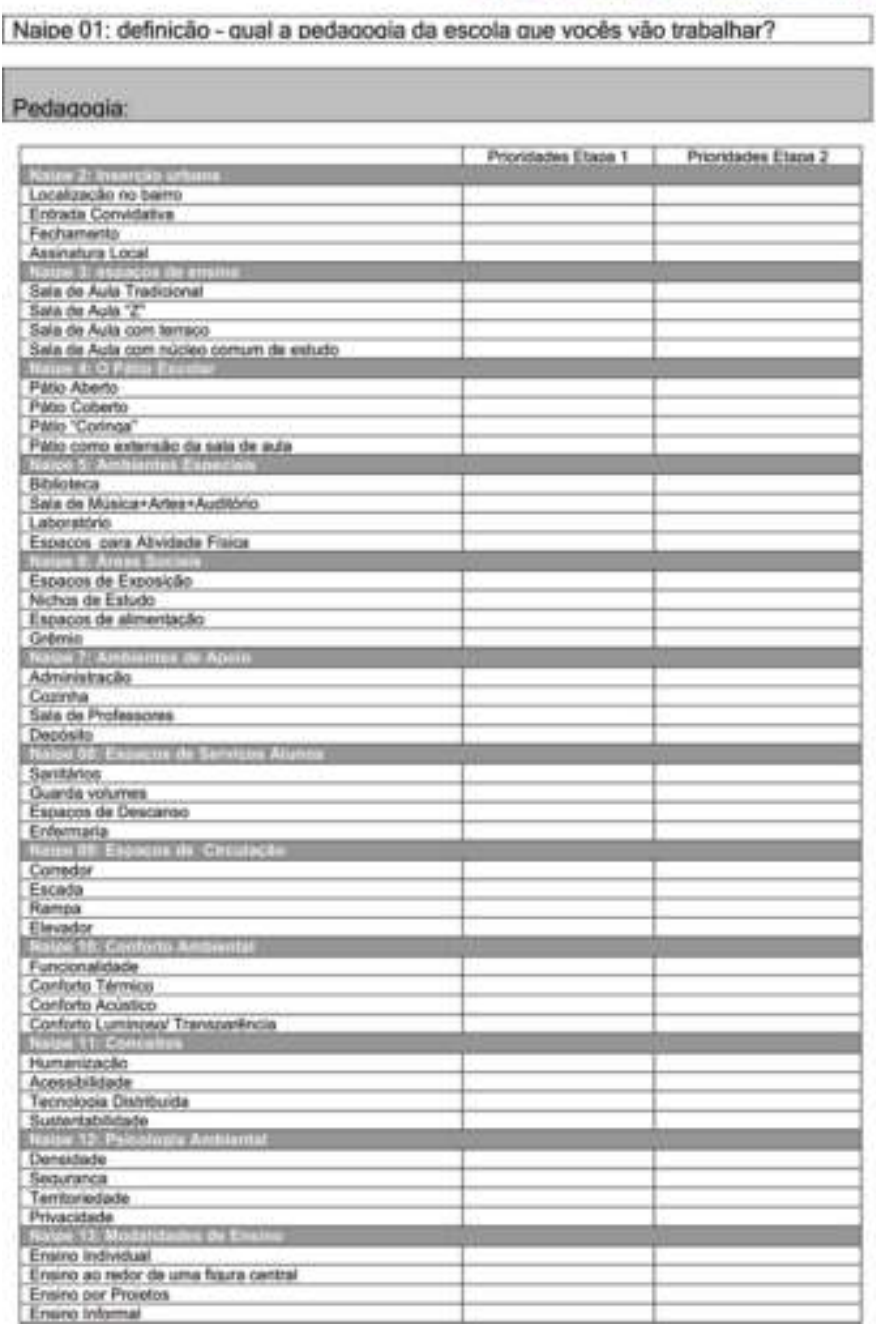

Fonte: As autoras

Para a aplicação desse teste, foi necessária a elaboração de fichas de apoio, que explicitassem aos alunos quais eram os conceitos e detalhes específicos de cada parâmetro de projeto estudado. Tais fichas foram desenvolvidas a partir da metodologia proposta pelo Problem Seeking de programação arquitetônica. Um exemplo dessas fichas encontra-se na Figura 3.

\section{Teste de verificação da capacidade da ferramenta em} apoiar o processo participativo de programação

Para este teste, foram realizadas 02 rodadas, sendo a primeira com arquitetos com experiência em diversas tipologias, inclusive a escolar e a segunda, com grupos de profissionais que incluíam arquitetos, engenheiros, administradores, pedagogos, pais, etc. Também foram simuladas situações de projeto, mas indicou-se que as definições como pedagogia, quantidade de alunos, turno da escola, etc. deveriam ser decididas no início da discussão. $\mathrm{O}$ objetivo desses testes foi verificar se a ferramenta era capaz de estimular os debates e contribuir para esclarecer a complexidade do processo 
de projeto escolar. Para essa aplicação, utilizaram-se como metodologia os Grupos Focais (MORGAN, 1997). Recomenda-se que esses grupos sejam formados por 68 participantes (nesse caso, possíveis usuários das escolas), um observador da seção (cuja função é registrar o desenvolvimento dos trabalhos, dificuldades encontradas, nível de participação dos usuários, etc.) e um mediador da discussão. $O$ início da seção deve ocorrer com a introdução do tópico de maneira direta e sem grandes aprofundamentos, para não direcionar a participação dos envolvidos. A seguir, apresentam-se as regras de trabalho, o moderador e o observador (MORGAN, 1997). Diferentemente de outras técnicas de reunião, seu objetivo é a sinergia entre as pessoas e não o consenso. Quanto mais ideias surgirem, melhor.

Para esse teste formou-se um grupo de 05 participantes, um moderador e um observador. O jogo foi apresentado como um todo. Depois, os participantes organizam as prioridades dentro de cada naipe, para se familiarizar com os tópicos essenciais a um projeto escolar e discutir cada parâmetro e a sua importância nas decisões projetuais.

\section{Resultados: a ferramenta do jogo de cartas}

O desenvolvimento desta pesquisa apresenta como resultado uma metodologia de projeto na forma de uma nova ferramenta de apoio ao processo de projeto arquitetônico, voltada para a etapa de programação. Criou-se de um Jogo de Cartas, baseado em parâmetros de projeto considerados importantes a arquitetura escolar. A seguir, apresenta-se uma síntese da definição geral do jogo, com os naipes e parâmetros selecionados, no Quadro 2. A Figura 4 exemplifica as cartas de cada naipe. $\mathrm{Na}$ sequência, uma breve explicação de cada um dos naipes que configuram o jogo de cartas.

Figura 3 - Exemplo de formulário organizador do programa arquitetônico

\section{Modalidades de Ensino: quais modalidades de ensino essa Dedaaoaia necessita?}

\begin{tabular}{|c|c|c|c|}
\hline Modalidade & Definicāo & Ambiente(s) onde ela deverá ser aplicada & Croquis \\
\hline $\begin{array}{l}\text { Ensino } \\
\text { Individual }\end{array}$ & $\begin{array}{l}\text { Espaço individual, silencioso, } \\
\text { de reflexdo e estudo, importante } \\
\text { para o aprendizado. Espaço } \\
\text { para atendimento individual, } \\
\text { dúvidas com o professor. }\end{array}$ & & \\
\hline $\begin{array}{c}\text { Ensino ao redor } \\
\text { de uma figura } \\
\text { central }\end{array}$ & $\begin{array}{l}\text { Refere-se ao modo de ensinar } \\
\text { focado em um especialista, que } \\
\text { compartilha seu conhecimento } \\
\text { com os alinos, ou seja, ensino } \\
\text { focado em uma figura central. }\end{array}$ & & \\
\hline Ensino Informal & $\begin{array}{l}\text { Refere-se ao modo de ensinar } \\
\text { mais informal, no qual } \\
\text { desenvolve-se habilidades } \\
\text { relativas ao discurso social e ao } \\
\text { aprendizado colaborativo. Aluno } \\
\text { ensina aluno: monitoria. }\end{array}$ & & \\
\hline $\begin{array}{c}\text { Ensino por } \\
\text { projetos }\end{array}$ & $\begin{array}{l}\text { Ensino focado em temas que } \\
\text { integram as diversas disciplinas. } \\
\text { Atividades com projetos em } \\
\text { maquetes ou outros formatos. }\end{array}$ & & \\
\hline
\end{tabular}

Fonte: As autoras 
DELIBERADOR, M.S.; KOWALTOWSKI, D.C.C.K

O jogo como ferramenta de apoio ao programa arquitetônico de escolas públicas

Quadro 02: jogo de cartas com seus naipes e parâmetros

\begin{tabular}{|c|c|c|c|c|}
\hline Naipe 01: Questões Pedagógicas & $\begin{array}{l}\text { Naipe 02: Questões } \\
\text { Urbanas }\end{array}$ & $\begin{array}{l}\text { Naipe 03: Espaços de } \\
\text { Ensino }\end{array}$ & Naipe 04: O Pátio Escolar & $\begin{array}{l}\text { Naipe 05: Ambientes } \\
\text { Especiais }\end{array}$ \\
\hline Pedagogias Tradicionais & Localização no bairro & $\begin{array}{l}\text { Sala de Aula } \\
\text { Tradicional }\end{array}$ & Pátio Aberto & Biblioteca \\
\hline \multirow[t]{2}{*}{ Pedagogias Alternativas } & Entrada Convidativa & Sala de Aula "Z" & Pátio Coberto & $\begin{array}{l}\text { Sala de Música + Artes + } \\
\text { Auditório }\end{array}$ \\
\hline & Fechamento & $\begin{array}{c}\text { Sala de Aula com } \\
\text { Terraço }\end{array}$ & Pátio Coringa) & Laboratório \\
\hline Ensino em turnos & $\begin{array}{l}\text { Assinatura local: } \\
\text { linguagem }\end{array}$ & $\begin{array}{l}\text { Sala de Aula com } \\
\text { Núcleo Comum de } \\
\text { Estudo }\end{array}$ & $\begin{array}{l}\text { Pátio como extensão da } \\
\text { sala de aula }\end{array}$ & $\begin{array}{l}\text { Espaços para Atividade } \\
\text { Física }\end{array}$ \\
\hline Naipe 06: Áreas Sociais & $\begin{array}{c}\text { Naipe 07: Ambientes de } \\
\text { Apoio } \\
\end{array}$ & $\begin{array}{l}\text { Naipe 08: Espaços de } \\
\text { Serviço dos Alunos }\end{array}$ & Naipe 09: Circulação & $\begin{array}{l}\text { Naipe 10: Conforto } \\
\text { Ambiental } \\
\end{array}$ \\
\hline Espaços de Exposição & Administração & Sanitários & Corredor & Funcionalidade \\
\hline Nichos de Estudo & Cozinha & Guarda volumes & Escada & Conforto Térmico \\
\hline Espaços de Alimentação & Sala de Professores & Espaços de Descanso & Rampa & Conforto Acústico \\
\hline Grêmio & Depósito & Enfermaria & Elevador & $\begin{array}{l}\text { Conforto Luminoso/ } \\
\text { Transparência }\end{array}$ \\
\hline Naipe 11: Conceitos & $\begin{array}{l}\text { Naipe 12: Psicologia } \\
\text { Ambiental }\end{array}$ & $\begin{array}{c}\text { Naipe 13: } \\
\text { Modalidades de } \\
\text { Ensino } \\
\end{array}$ & $\begin{array}{l}\text { Naipe 14: Aspectos de } \\
\text { Comportamento }\end{array}$ & Naipe 15: Público Alvo \\
\hline Humanização & Densidade & $\begin{array}{c}\text { Ensino ao redor de } \\
\text { uma figura central } \\
\text { "Campfire" }\end{array}$ & Vandalismo & Alunos \\
\hline Acessibilidade & Segurança & $\begin{array}{l}\text { Ensino informal } \\
\text { "Watering Hole" }\end{array}$ & Timidez & $\begin{array}{c}\text { Professores + } \\
\text { Coordenador+ } \\
\text { Diretor }\end{array}$ \\
\hline Tecnologia Distribuída & Territoriedade & $\begin{array}{l}\text { Ensino individual } \\
\text { "Cavespace" }\end{array}$ & Bullying & Funcionários \\
\hline Sustentabilidade & Privacidade & Ensino por projetos & Drogas & Pais \\
\hline Naipe 16: Áreas & Naipe 17: Zonamento & & & \\
\hline Área da Sala de Aula & Pátio Central & & & \\
\hline Tamanho da escola & $\begin{array}{l}\text { Salas de aula com } \\
\text { corredor central }\end{array}$ & & & \\
\hline Tamanho da turma & Quadra Superior & & & \\
\hline Áreas livres & Quadra Central & & & \\
\hline
\end{tabular}

Fonte: As autoras

Figura 4 - Exemplo de naipe do jogo de cartas: Naipe 13: Modalidades de Ensino
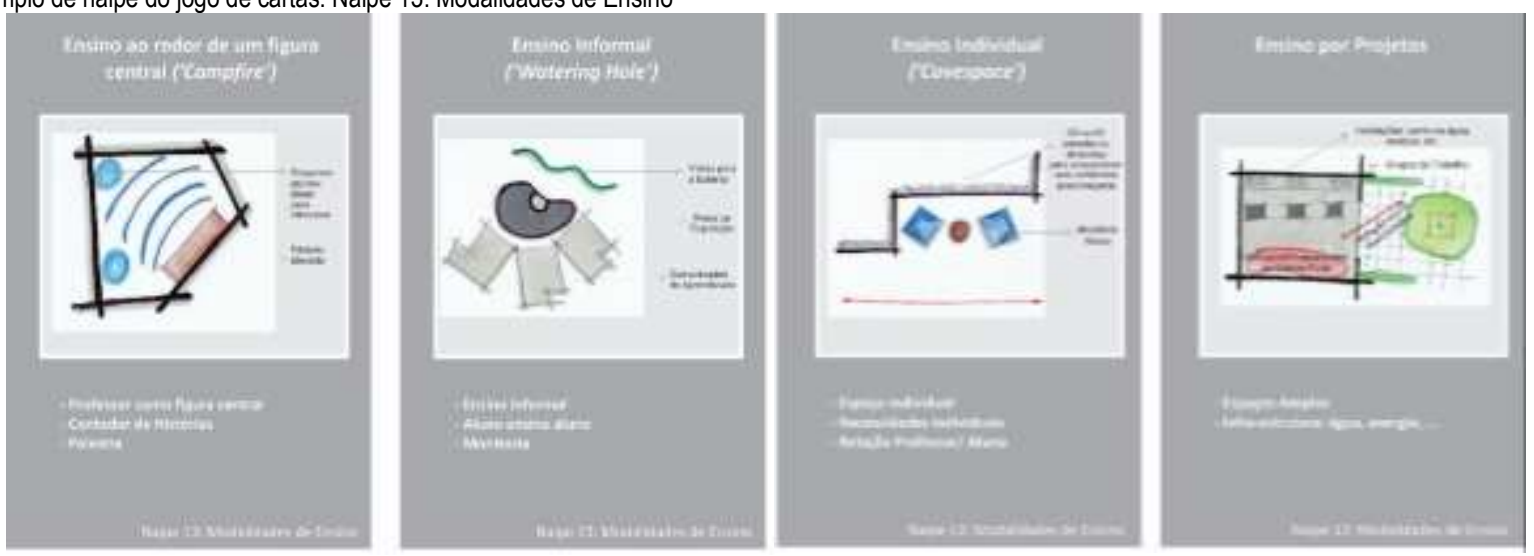

Fonte: As autoras 


\section{Naipe 1: Questões Pedagógicas}

Dada a importância da discussão dos aspectos pedagógicos para a constituição de um novo ambiente escolar, justifica-se a elaboração deste primeiro naipe. A ideia é que o projetista atente para as necessidades espaciais específicas da pedagogia da escola a ser projetada, mas também tome contato com outras possibilidades que possam enriquecer sua proposta.

Para a definição das cartas desse naipe, observou-se, primeiramente, que, nas escolas públicas brasileiras, há um predomínio do ensino tradicional, que pode estar fundamentado em diversas correntes pedagógicas. As correntes tradicionais têm como objetivo a organização dos espaços de ensino em torno da figura central de um professor (SAVIANI, 2009). Nesse modelo educacional, o foco está no professor como figura central do aprendizado. Em contraposição, a essas correntes pedagógicas, existem outras alternativas tais como a Pedagogia Waldorf, Montessori, Construtivista, entre outras.

Além das pedagogias propriamente ditas, outro aspecto que impacta a arquitetura escolar é como a escola organiza o seu funcionamento, ou seja, como são os turnos de entrada e saída dos alunos. O ensino integral é parte das políticas públicas educacionais do país (BRASIL, 2014). Entretanto, o ensino em turnos ainda é bastante comum na realidade brasileira, dependendo da escola podendo ser dividido em até três períodos.

\section{Naipe 2: Inserção Urbana}

Esta temática é importante, especialmente para projetos públicos. Aspectos relacionados a ela são: a questão da localização no bairro, os aspectos de fechamento (uma vez que influenciam os acessos, a segurança e a relação entre o espaço interno e externo), a linguagem arquitetônica do edifício escolar (muitas vezes a única referência arquitetônica nos bairros periféricos) e a entrada, que deve ser convidativa e atender algumas funções urbanas específicas do ambiente escolar (oferecer abrigo aos pais, espaço de espera, etc.).

\section{Naipe 03: Espaços de Ensino}

A discussão sobre o ambiente ideal de sala de aula é vasta. Esse naipe discute os diversos tipos de das salas de aula, tais como a tradicional, a sala de aula em formato de $Z$, as salas com terraço e a formação de conjuntos de salas com áreas de apoio compartilhadas.

\section{Naipe 04: 0 pátio escolar}

O espaço do pátio tem igual importância em relação às salas de aula, uma vez que nesses espaços se complementam as atividades de ensino e se realizam atividades de sociabilização. Diversos são os tipos de pátio que podem ser incorporados ao projeto escolar, como o Pátio Aberto; o Pátio Coberto; o Pátio Coringa (pátio que abraça todas as atividades que não possuem local específico e determinado para sua realização) e o Pátio como extensão da sala de aula.

\section{Naipe 5: Ambientes Especiais}

A literatura indicou que a escola atual demanda espaços apropriados para abrigar atividades diversificadas, consideradas pedagogicamente importantes. As bibliotecas, laboratórios, espaços de atividades físicas (além da quadra coberta) e de artes e música tornaramse essenciais.

\section{Naipe 6: Áreas Sociais}

A escola se constitui não só no espaço de aprendizado de conteúdos, mas também é o espaço de formação e socialização das crianças. Desse modo, o prédio escolar deve oferecer ambientes apropriados para o atendimento dessas necessidades educativas. Os espaços de alimentação podem assumir esse papel, assim como os nichos de estudo, o grêmio e as áreas de exposição.

\section{Naipe 7: Ambientes de Apoio}

Garantir o bom funcionamento do ambiente escolar significa prover o espaço de ambientes de apoio amplos, bem projetados e bem distribuídos no edifício. A área administrativa deve refletir a organização e o bom funcionamento da escola. As salas de professores indicam a valorização do corpo docente. Cozinhas e depósitos devem receber atenção para permitir que suas atividades sejam corretamente desempenhadas, não prejudicando a funcionalidade do ambiente escolar.

\section{Naipe 8: Espaços de Serviço aos Alunos}

Os espaços de serviço aos alunos merecem atenção. Sanitários devem ser amplos e bem distribuídos no edifício. As áreas de descanso e de guarda-volumes são importantes, especialmente em escolas de turno integral. Por fim, a enfermaria ou espaço destinado à espera da criança por socorro ou atendimento específico também deve entrar na discussão desta temática.

\section{Naipe 9: Espaços de Circulação}

Embora nem sempre mencionados, no caso do ambiente escolar, esses são espaços importantes, pois influenciam os aspectos de segurança e de funcionalidade (fluxos) do edifício. São espaços de socialização e também áreas onde geralmente manifestam-se práticas negativas de comportamento (CARVAlHOSA, 2010). Assim, as rampas, escadas, 
elevadores e os corredores devem ser discutidos como partes importantes do projeto escolar.

\section{Naipe 10: Conforto Ambiental}

O conforto ambiental é aspecto essencial para a garantia do bem estar de toda a comunidade escolar e também possui implicações para a saúde e produtividade desses usuários. Todos os aspectos de conforto são importantes, desde os aspectos de funcionalidade até os aspectos de térmica, acústica e iluminação, sendo que todos devem fazer parte do projeto desde as fases iniciais.

\section{Naipe 11: Conceitos}

Existem conceitos essenciais na proposição de arquitetura escolar de qualidade. Humanização, sustentabilidade, Tecnologia Distribuída e Acessibilidade são alguns desses conceitos, cuja correta aplicação colabora sensivelmente com a melhoria do ambiente escolar.

\section{Naipe 12: Psicologia Ambiental}

Os conceitos de psicologia ambiental permitem que as crianças ganhem sentimento de pertencimento ao espaço escolar, garantindo que o aprendizado seja pleno e efetivo (GIFFORD, 2001). A lotação (densidade) dos ambientes de ensino, as questões de territoriedade, de segurança psicológica e de privacidade são assuntos que devem ser incluídos na discussão do programa.

\section{Naipe 13: Modalidades de Ensino}

A literatura indica modalidades de ensino que necessitam de espaços específicos para a realização de suas atividades. Assim, o ensino ao redor de uma figura central "Campfire", o ensino informal "Watering Hole", o ensino individual "Cavespace" e o ensino por projetos resumem essas modalidades de atuação pedagógica importantes à maioria das pedagogias atuais.

\section{Naipe 14: Aspectos Comportamentais Típicos do Ambiente Escolar}

Outro aspecto importante que deveria ser discutido na etapa do programa são as questões comportamentais. $\mathrm{O}$ bullying, o vandalismo, as drogas e a timidez muitas vezes poderiam ser evitados ou minimizados dependendo das qualidades espaciais do edifício (KOWALTOWSKI, 2011; GARVALHOSA, 2010).

\section{Naipe 15: Público Alvo}

O público principal das escolas são os alunos. Entretanto, ao programar, não se podem esquecer outros agentes importantes e atuantes no ambiente escolar, como pais, funcionários e professores.

\section{Naipe 16: Áreas e Dimensionamentos}

Para um programa completo são necessárias referências das medidas, dimensões, áreas e relações funcionais, assim como a população de alunos da escola. As áreas dos ambientes de ensino, as áreas livres, o tamanho das turmas e da escola como um todo, devem fazer parte da etapa de programação.

\section{Naipe 17: Zoneamento}

As relações dos ambientes afetam a funcionalidade e o conforto ambiental de uma instituição de ensino. Nesse sentido, o agrupamento dos conjuntos funcionais necessita de uma reflexão para um bom entendimento das interferências e orientação das decisões projetuais.

\section{Resultados: aplicação dos testes}

O resultado desta pesquisa é a elaboração de um jogo de cartas para apoio à fase de programa arquitetônico. $\mathrm{O}$ jogo foi desenvolvido em diversas versões, aprimoradas a partir de diversos testes realizados, conforme descritos nos procedimentos metodológicos. Foram aplicados três tipos de testes, descritos a seguir.

\section{Aplicação I - Teste de verificação da compreensão do conteúdo pelos possíveis participantes do jogo de cartas}

$\mathrm{Na}$ primeira rodada desse teste um arquiteto experiente em ilustrações e com experiência na arquitetura escolar foi convidado para avaliar o jogo, focando principalmente a questão das ilustrações. Diversas sugestões para alterações foram feitas, no sentido de evidenciar o conceito discutido em cada carta. Para a carta de humanização, por exemplo, sugeriu-se uma imagem de uma escola cuja arquitetura remetesse à arquitetura doméstica, com elementos da natureza e a escala humana. Para a carta de segurança psicológica, sugeriu-se substituir a imagem do círculo por uma imagem de triângulo. Isso se justifica em razão do triângulo já ser utilizado em outras sinalizações de segurança e por ser uma figura instável, que pode transparecer instabilidade quando apenas encosta um vértice na base. As alterações foram realizadas, e o jogo foi submetido a novos testes. Nessas novas rodadas, organizaram-se seções com grupos de profissionais envolvidos com a tipologia escolar, ou seja, arquitetos, engenheiros, pedagogos, professores, funcionários da administração pública, etc., conforme a Figura 5. Apresentou-se cada naipe e solicitou-se uma simulação de projeto escolar e a ordenação das cartas em prioridades. 

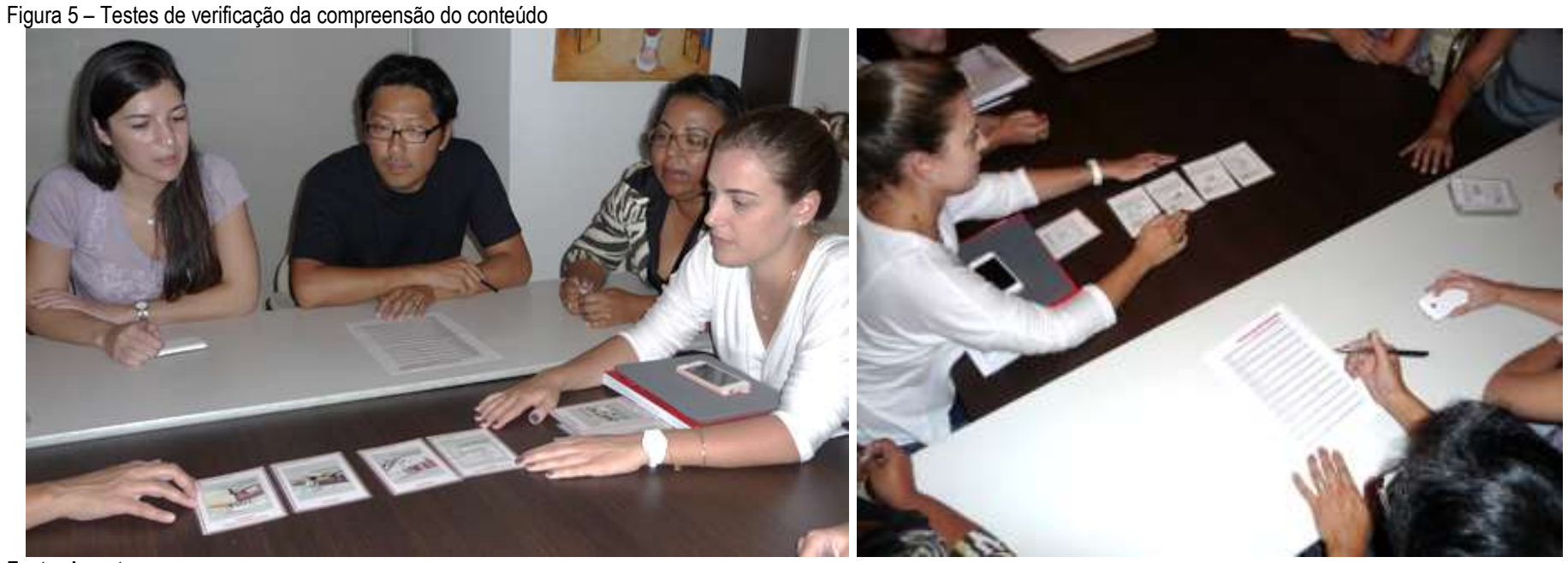

Fonte: As autoras

Em termos dos resultados dessa aplicação, pode-se afirmar que o jogo foi compreendido pelos participantes. Afirmou-se a qualidade da ferramenta, considerada como capaz de contribuir com a discussão sobre a arquitetura escolar. Esses grupos também sugeriram ajustes em algumas imagens, buscando maior uniformidade em cada um dos naipes. Após o primeiro teste, percebeu-se a necessidade da inclusão de palavras de apoio para facilitar a compreensão dos conceitos. Quanto às figuras humanas, sugeriu-se que ficassem mais leves, para não serem o primeiro plano das ilustrações. Exemplos dos ajustes implementados nas imagens e das diferentes versões do jogo encontram-se na Figura 6.

Outra modificação sugerida foi a reordenação dos naipes, buscando maior coerência para a estrutura da discussão na fase de programa. Ajustes foram feitos, reordenando os 17 naipes, conforme o Quadro 2.

Aplicação II - Teste de verificação da capacidade de apoiar o desenvolvimento da programação

arquitetônica escolar.

O jogo também foi testado para apoio ao desenvolvimento completo de um programa arquitetônico, em situação acadêmica. Para isso, três turmas de terceiro ano de escolas de arquitetura e urbanismo (cuja disciplina de projeto possui como tema o desenvolvimento de um edifício escolar), foram convidadas e o jogo foi aplicado, conforme Figura 7. Após a aplicação com a primeira turma, observou-se a necessidade de ajustes nas fichas de apoio, que deveriam apresentar exemplos e algumas explicações conceituais. Essas modificações foram realizadas e novas aplicações foram feitas. As fichas ajustadas funcionaram de forma efetiva, com resultados bastante satisfatórios. Observou-se que, com a aplicação do jogo de cartas, os alunos foram capazes de criar programas arquitetônicos completos e enriquecidos, com os conceitos do jogo incorporados. Os alunos também mencionaram que o jogo facilitou a compreensão da complexidade do projeto escolar, sistematizando as temáticas essenciais de forma didática. $\mathrm{Na}$ avaliação dos projetos, ambientes com propostas mais inovadoras, como salas de aula $\mathrm{Z}$ e salas com terraço (entre outras) apareceram com mais frequência, em comparação às experiências anteriores desta pesquisa.

\section{Aplicação III - Teste de verificação da capacidade de apoiar o processo participativo de programação.}

Para finalizar a etapa de testes, o jogo foi submetido a novas sessões, visando a verificar sua eficiência no estímulo aos debates, esclarecendo também a complexidade da tipologia escolar. Duas rodadas foram realizadas, ambas através da metodologia dos Grupos Focais. Na primeira rodada, conforme a Figura 8, um grupo de arquitetos acostumados à realidade brasileira e experientes em diversas tipologias foi convidado a conhecer o jogo. $\mathrm{O}$ resultado apresentou-se como uma discussão aprofundada e, principalmente, muito focada aos temas de cada um dos naipes. Os arquitetos mencionaram que a ferramenta contribui para demonstrar a complexidade do projeto arquitetônico escolar, podendo, também, servir para apresentar tal complexidade a possíveis clientes. Todos acreditam que a ferramenta possui grande aplicabilidade à arquitetura escolar, sugerindo-se, inclusive, a criação de novos jogos para outras tipologias.

$\mathrm{Na}$ segunda rodada, com os grupos de profissionais envolvidos com a tipologia escolar, a situação não se mostrou diferente. $\mathrm{O}$ debate foi bastante rico e focado e a ferramenta muito bem aceita. Notou-se, no entanto, a necessidade de criar um manual de uso da mesma, para que ela possa ser usada por outros profissionais, independentemente da presença das criadoras do jogo. 
Também notou-se a necessidade de se elaborar algum instrumento capaz de sistematizar as informações básicas de programação, tais como pedagogia, número de alunos, turno, tamanho das turmas, etc.. Tais instrumentos encontram-se em desenvolvimento.
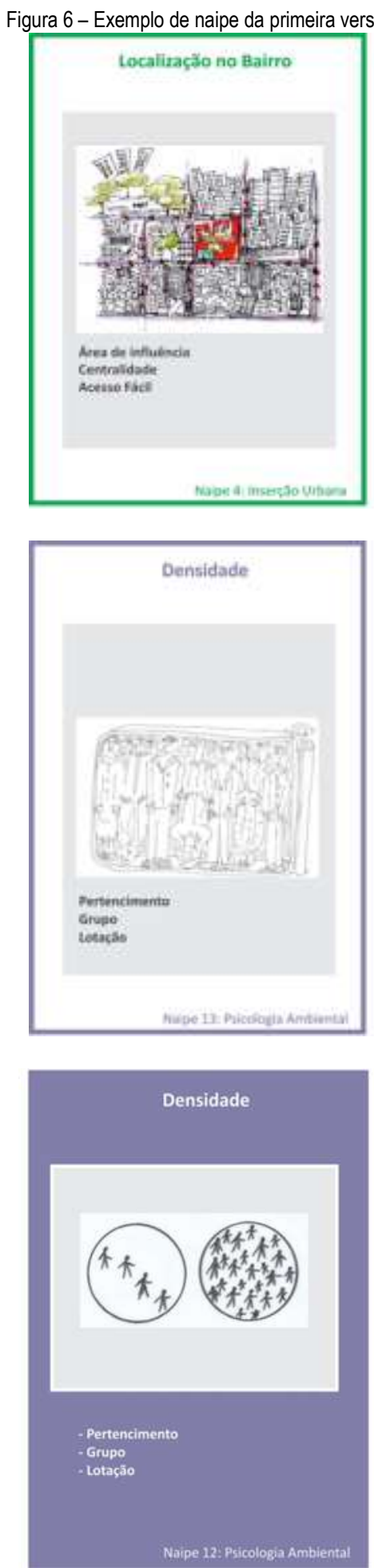

Fonte: As autoras
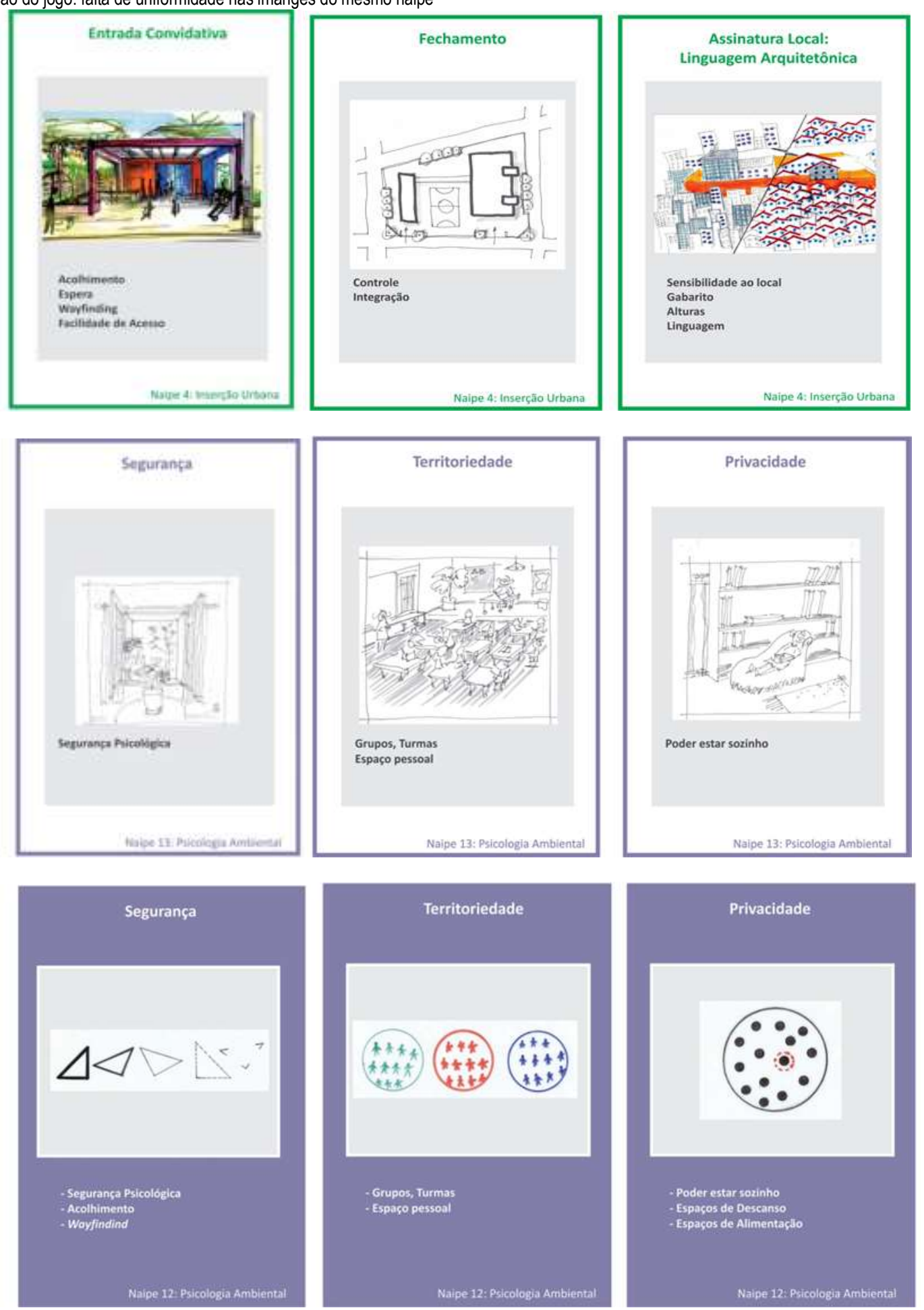

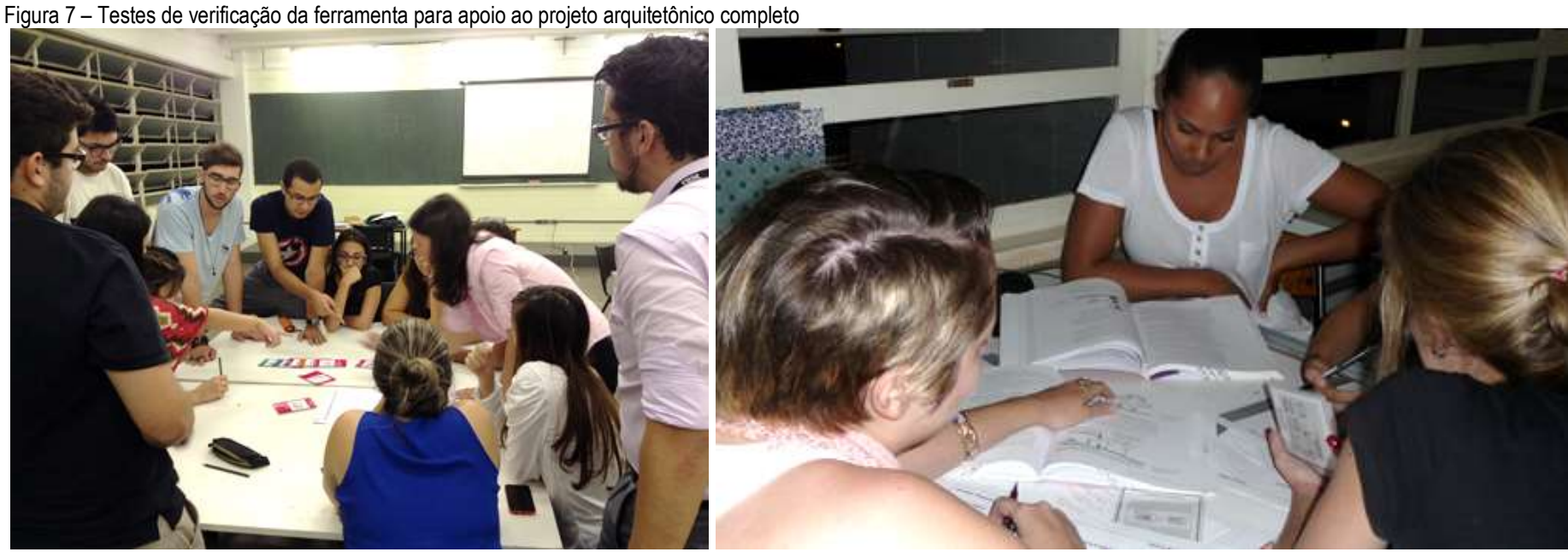

Fonte: As autoras

Figura 8 - Testes de verificação da ferramenta para apoio ao processo participativo de programação

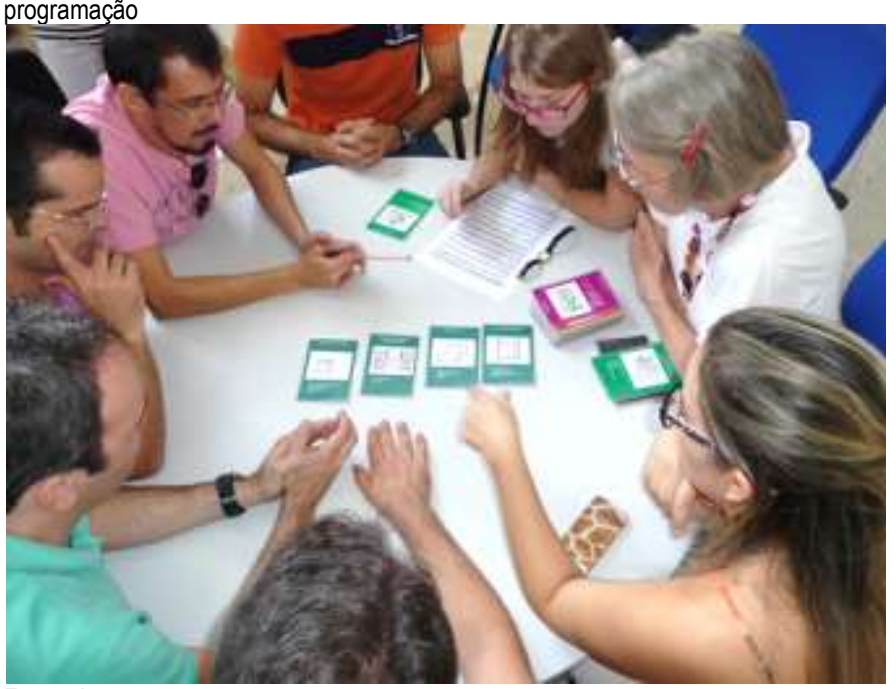

Fonte: As autoras

\section{Conclusão}

A criação de uma ferramenta de apoio ao programa arquitetônico, no formato de um jogo de cartas, teve como principal objetivo estimular os debates sobre arquitetura escolar. Outro objetivo foi aprofundar o conhecimento sobre a complexidade dessa tipologia e discutir a importância da qualidade do ambiente escolar.

Pode-se afirmar que uma das contribuições desta pesquisa foi reunir grande quantidade de informações antes dispersas pela literatura, como um método capaz de ser aplicado diretamente ao processo de projeto escolar. Os dados encontram-se formatados adequadamente e resumidos no jogo, de forma a possibilitar fácil aplicação na etapa de programação. $\mathrm{O}$ jogo também pode ser utilizado como checklist, na avaliação de propostas de projeto.
Embora elaborado a partir de um formato clássico de jogo de cartas, o jogo representa uma nova metodologia à etapa de programa arquitetônico, que foi testada em diversas situações. Esses testes demonstraram que a ferramenta estimula uma reflexão aprofundada sobre as temáticas consideradas essenciais à arquitetura escolar de qualidade. Os parâmetros que fundamentaram a ferramenta foram trazidos de diversas áreas e referências da literatura e adaptados à realidade brasileira, através da comparação com os requisitos funcionais da FDE e através dos testes aplicados.

A nova ferramenta representa uma contribuição para a área de metodologia de projeto. Para o desenvolvimento da ferramenta em forma de jogo, também se observou a importância do estudo de imagens. No caso do jogo de cartas desta pesquisa, essa importância se dá para que os desenhos elaborados sejam apropriados para o objetivo da pesquisa. Sabe-se que o desenho é a linguagem da arquitetura, no entanto, na etapa do programa, desenhos inapropriados poderiam induzir as decisões dos participantes, dependendo da forma como se apresentassem. Nesse sentido, buscou-se elaborar as ilustrações de forma a não trazer uma solução pronta (não é o objetivo da fase de programa), garantindo a representação correta dos conceitos e o estímulo à discussão. Também a definição das palavras que compõem cada carta foi feita, focando no aprofundamento da reflexão especialmente para os conceitos menos conhecidos.

A utilização desse jogo como método também se mostrou muito eficaz pois estrutura um debate, focando a atenção dos participantes. A ferramenta torna a discussão mais efetiva e produtiva, oferecendo um produto final de valor para as próximas fases do processo de projeto. 
O jogo apresentado não é uma ferramenta fixa e definitiva. Isso se deve ao fato de tratar-se de apoio ao processo de projeto, devendo, portanto, se constituir em um instrumento dinâmico e capaz de adaptar-se a cada realidade trabalhada. Assim, esse jogo mostra-se como uma base para a arquitetura escolar de modo geral, mas devem sempre ser incentivadas as discussões sobre acréscimos ou particularidades inerentes a cada novo processo. Definições quantitativas, por exemplo, demandam reflexões específicas, tais como medições, levantamentos e cálculos. Ambientes especiais, como outro exemplo, também não se esgotam nos parâmetros das cartas propostas, podendo serem inseridos outros ambientes ou substituídos de acordo com a necessidade local. Vislumbra-se que a medição da melhoria da qualidade de projetos escolares seja possível a partir da aplicação em casos reais. Sabe-se que o incremento dos debates, durante o processo de projeto, contribui para o incremento da qualidade das propostas de projeto. Os arquitetos participantes dos testes afirmaram ganhos de conhecimento e a expectativa de uso do jogo na sua atividade profissional.

Acredita-se que uma ferramenta de apoio ao processo de projeto desse tipo poderá ter grande repercussão na construção de futuras edificações escolares, o que significa a tradução direta de um trabalho científico à prática arquitetônica e ao ensino de projeto. Almeja-se que esse jogo possa ser aplicado por instituições públicas, como a FDE ou o MEC, na busca pela construção de melhores espaços das escolas públicas. Para os trabalhos futuros, pretende-se a continuação do desenvolvimento do jogo, através da criação de novos suportes mencionados nos resultados e possíveis inclusões de novos naipes a partir de discussões sobre outras temáticas atuais, como por exemplo, as questões de segurança patrimonial, de materiais e de manutenção.

\section{Agradecimentos}

Os autores agradecem à FAPESP, pelo apoio para o desenvolvimento das pesquisas que originaram esse artigo.

\section{Referências}

ALEXANDER, C.; ISHIKAWA, S.; SILVERSTEIN, M. Uma linguagem de padrões. Bookman, Porto Alegre, 2013.

ANTUNES, E.; RAMOS, L.; JESUS, L.; OLIVEIRA, H. Avaliação da qualidade ambiental em escolas: o caso da UMEF Dr. Tuffy Nader, Vila Velha-ES. In: ENCONTRO NAGIONAL DE TEGNOLOGIA NO AMBIENTE CONSTRUÍDO, 15. 2014, Maceió. Anais... . Maceió: ANTAC, 2014, p.2013-2022. Disponível em: http://www.infohab.org.br/entac2014/artigos/paper 258.pdf. Acesso em: dez. 2014.

BRANDT, E.; MESSETER, J. Facilitating collaboration through design games. In: CONFERENCE ON PARTICIPATORY DESIGN: Artful integration: interweaving media, materials and practices, 8., Vol. 1, Toronto. Proceedings... . New York: ACM, 2004, p. 121-131. Disponível em: http://dl.acm.org/citation.cfm?doid=1011870.1011885. Acesso em: dez. 2014.

BRANDT, E. Designing exploratory design games: a framework for participation in participatory design? In: conference on Participatory design: Expanding boundaries in design 9. Vol. 1, Cophehagen. Proceedings ... New York: ACM, 2006, p.57-66. Disponível em: http://dl.acm.org/citation.cfm?doid=1147261.1147271. Acesso em: dez. 2014.

BRASIL, Lei n ${ }^{\circ}$ 13005, de 25 de junho de 2014. Aprova o Plano Nacional de Educação - PNE e dá outras providências. Lex: Presidência da República. Diário Oficial da União. Brasília: República Federativa do Brasil. 2014. p. 2-7. Disponível em: http://www2.camara.leg.br/legin/fed/lei/2014/lei-13005-25-junho-2014-778970-publicacaooriginal-144468-pl.html. Acesso em: ago. 2014.

CABE. Commission for Architecture and the Built Environment (CABE). Being involved in school design. London, 2004. Disponível em: http://webarchive.nationalarchives.gov.uk/20110118095356/http://www.cabe.org.uk/files/being-involved-inschool-design.pdf. Acessado em: ago. 2014.

CABE. Commission for Architecture and the Built Environment (CABE). Successful School Design: how CABE's school design panel Works: Bsf waves 1-4. London, 2009. Disponível em: http://dera.ioe.ac.uk/id/eprint/9494. Acesso em: ago. 2014.

CARVALHOSA, S. Prevenção da Violência e do Bullying em Contexto Escolar. Lisboa: Climepsi Editores, 2010. 
CAVALIERE, Ana Maria Villela. Educação integral: uma nova identidade para a escola brasileira?. Educ. Soc., Campinas , v. 23, n. 81, p. 247-270, Dec. 2002. Disponível em: http://www.scielo.br/scielo.php?script=sci_arttext\&pid=S0101-

73302002008100013\&lng=en\&nrm=iso. Acesso em: dez. 2014. http://dx.doi.org/10.1590/S0101-73302002008100013.

DELIBERADOR, M. S. O processo de projeto de arquitetura escolar no Estado de São Paulo: caracterização e possibilidades de intervenção. 2010. Dissertação (Mestrado) - Programa de Pós-Graduação em Engenharia Civil, Faculdade de Engenharia Civil, Arquitetura e Urbanismo, Universidade Estadual de Campinas, Campinas, SP.

DESIGN, I. O. C.; FURNITURE, V. S.; DESIGN, B. M. The Third Teacher: 79 Ways You Can Use Design to Transform Teaching \& Learning. New York: Abrams Books, 2010.

DUDEK, M. Architecture of Schools: the new Learning Environments. Oxford: Architectural Press, 2000.

DUDEK, M. Schools and Kindergartens - a design manual. Berlin: Birkhäuser Verlag AC, 2007.

DURÁN-NARUCKI, V. School building condition, school attendance, and academic achievement in New York City public schools: A mediation model. Journal of Environmental Psychology, v. 28, n. 3, p. 278-286, 2008. Disponível em: http://dx.doi.org/10.1016/j.jenvp.2008.02.008. Acesso em: Acesso em: 8 jan. 2014

EARTHMAN, G. I.. School facility conditions and student academic achievement. Williams Watch Series: Investigating the Claims of Williams v. State of California, Los Angeles: UCLA Institute for Democracy, Education \& Access, out. 2002. Disponível em: http://escholarship.org/uc/item/5sw56439. Acesso em: 8 jan. 2014.

ELALI, G. A.; SOUZA, H. S. Avaliação de escolas da rede pública de ensino fundamental e médio em Natal-RN. (2011-2012). Natal: Grupo de Pesquisa em Projeto de Arquitetura e Percepção do Ambiente - UFRN, 2011. Disponível em: < http://hdl.handle.net/123456789/944>. Acesso em: dez. 2014.

FDE (Fundação para o Desenvolvimento da Educação). Disponível em: http://www.fde.sp.gov.br/pagespublic/Home.aspx . Acesso em 25 de abril de 2015.

FISHER, K. Pedagogy and architecture. Architecture Australia, v. 96, n. 5, p. 55-57, 2007.

FRANÇA, A.J.L.; ORNSTEIN, S.W. Técnicas de gestão da qualidade aplicadas ao diagnóstico de avaliação pós ocupação (APO). In: ENCONTRO NACIONAL DE TEGNOLOGIA NO AMBIENTE CONSTRUÍDO, 15. 2014, Maceió. Anais... . Maceió: ANTAC, 2014, p.1814-1823. Disponível em: http://www.infohab.org.br/entac2014/artigos/paper 36.pdf. Acesso em: dez. 2014.

GIFFORD, R. Environmental Psychology: Principles and Practice. 3. ed. [s.1.] Optimal Books, 2001.

GIL, A.C. Métodos e técnicas de pesquisa social. São Paulo: Editora Atlas, 2008.

HABRAKEN, H. J.; GROSS, M. D. Concept design Games. Design Studies, v. 9, n. 3, p. 150-158, jul. 1988. Disponível em: http://www.sciencedirect.com/science/article/pii/0142694X88900440. Acesso em: 8 jan. 2014. http://dx.doi.org/10.1016/0142$694 \mathrm{X}(88) 90044-0$

HERSHBERGER, R.G. Architectural Programming and Predesign Manager. New York: Mc Graw-Hill, 1999.

HIGGINS, S.; HALL, E.; WALL, K.; WOOLNER, P.; MCCAUGHEY, C. The impact of school environments: A literature review. Design Council, 2005. Disponível em: http://www.ncl.ac.uk/cflat/news/DCReport.pdf. Acessado em: dez. 2014.

HILLE, T. Modern Schools: A Century of Design for Education. Hoboken: Wiley, 2011.

INEP- Instituto Nacional de Estudos e Pesquisas Educacionais. Disponível em: http://www.inep.gov.br/. Acesso em: 28 abr. 2015.

ISO - INTERNATIONAL ORGANIZATION FOR STANDARDIZATION. ISO 9699: 1994. Geneva, SW: International Organization for Standardization, 2004. Disponível em: http:/www.iso.org/iso/en/CatalogueDetailPage. Acesso em: dez. 2014. 
KOWALTOWSKI, D. C. C. K. Arquitetura escolar: o projeto do ambiente de ensino. 1. ed. São Paulo, SP: Oficina de Textos, 2011.

KOWALTOWSKI, D. C. C. K.; MOREIRA, D. C.; DELIBERADOR, M. S.. O programa arquitetônico no processo de projeto: discutindo a arquitetura escolar, respeitando o olhar do usuário. In: SALGADO, Mônica Santos; RHEINGANTZ, Paulo Afonso (Org.). Projetos Complexos e os Impactos na Cidade e na Paisagem. Rio de Janeiro: Editora da UFRJ, 2012. p. 160-185.

KOWALTOWSKI, D. C. C. K.; DELIBERADOR, M. S.; PEREIRA, P. R. P. Designing the positive public school environment: a Brazilian perspective. In: ZANNIN, P. H. T. (Ed.) Noise and ergonomics in the workplace. [Hauppauge] New York: Nova Publishers, 2013. p. 1-33

MEG - Ministério da Educação. Pátria Educadora: A Qualificação do Ensino Básico como Obra de Construção Nacional. Disponível em: http://pne.mec.gov.br/images/pdf/Noticias/Patria_Educadora_documento_preliminar_SAE.pdf. Acesso em: 22 abr. 2015.

MOREIRA, D. de C.; KOWALTOWSKI, D. C. C. K. Discussão sobre a importância do programa de necessidades no processo de projeto em arquitetura. Ambiente Construído, Porto Alegre, v. 9, n. 2, p. 31-45, abr./jun. 2009. Disponível em: http://seer.ufrgs.br/index.php/ambienteconstruido/article/view/7381/5484. Acesso em: dez. 2014.

MORGAN, D.L. Focus Groups as qualitative research. Thousand Oaks: Sage Publications, 1997.

NAIR, P.; FIELDING, R.; LACKNEY, J. The language of school design. Design patterns for the 21st century school. National Clearinghouse for Educational Facilities, India, 2009.

ORNSTEIN, S. W.; MOREIRA; N. S.; ONO, R.; FRANÇA, A.J.G. L. ; NOGUEIRA, R. A.M.F. Improving the quality of school facilities through building performance assessment: Educational reform and school building quality in São Paulo, Brazil. Journal of Educational Administration, v. 47, n. 3, p. 350 - 367, 2009. Disponível em: http://www.emeraldinsight.com/doi/full/10.1108/09578230910955782. Acesso em: dez. 2014. http://dx.doi.org/10.1108/09578230910955782

ORNSTEIN, Sheila Walbe et al. Post-Occupancy Evaluation in Brazil. Its impact on professional practice. In: MALLORYHILL, Shauna; PREISER, Wolfgang F.E.; WATSON, Christopher (Org.). Enhancing Building Perfomance. 1 ed., New York: Wiley-Blackwell, v. 1, p. 247-258, 2012.

PEÑA, W. M.; PARSHALL, S. A. Problem Seeking: An Architectural Programming Primer. New York: John Wiley and Sons, 2012.

PEREIRA, P. R. P. Método de análise de precedentes para apoio ao projeto da arquitetura escolar pública do estado de São Paulo. 2013. Tese (Doutorado) - Programa de Pós-graduação em Arquitetura, Tecnologia e Cidade, Faculdade de Engenharia Civil, Arquitetura e Urbanismo, Universidade Estadual de Campinas, 2013.

SANOFF, H. School Design. New York: John Willey and Sons, 1994.

SANOFF, H. School Building Assessment Methods. Washington: National Glearinghouse for Educational Facilities, 2001.

SAVIANI, D. Escola e democracia. Campinas: Autores Associados, 2009.

TARALLI, G. H. Espaços De Leitura Na Escola: Salas De Leitura / Bibliotecas Escolares. Boletim Salto Para o Futuro MEC, Rio de Janeiro, 2004, p. 31-39.

TAYLOR, A. P.; ENGGASS, K. Linking architecture and education sustainable design for learning environments. Albuquerque: University of New Mexico Press, 2008.

WALDEN, R. (Ed). Schools for the Future: designs proposals from architectural psychology. Hogrefe, Germany: Springer, 2009.

WEINSCHENK, S. 100 things every designer needs to know about people. Berkeley: New Rider, 2011. 
WOOLNER, P. Building Schools for the Future through a participatory design process: exploring the issues and investigating ways. In: ANNUAL CONFERENCE OF THE BRITSH EDUCATIONAL RESEARCH ASSOCIATION, 2009, Manchester. Proceedings ... London: BERA, 2009, p. 1-17.

WOOLNER, P. The Design of Learning Spaces. London: Continuum, 2010.

\section{${ }^{1}$ Marcella Savioli Deliberador}

Arquiteta. Doutoranda na Universidade Estadual de Campinas-SP. Universidade Estadual de Campinas. Faculdade de Engenharia Civil, Arquitetura e Urbanismo. Av. Albert Einstein, 951 Campinas-SP CEP 13083-852, Brasil.

\section{${ }^{2}$ Doris G.C.K. Kowaltowski}

Arquiteta. PhD, Professora Titular e Colaboradora do Departamento de Arquitetura e Construção. Universidade Estadual de Campinas. Faculdade de Engenharia Civil, Arquitetura e Urbanismo. Av. Albert Einstein, 951 Campinas-SP CEP 13083-852, Brasil. 